\title{
Simultaneous Effect of Kisspeptin and Galanin on Serum Luteinizing Hormone and Testosterone Levels in Male Rats
}

\author{
Maliheh Talebolhosseini, Homayoun Khazali $\bowtie$
}

Department of Physiology, Faculty of Biological Sciences, Shahid Beheshti University, Tehran, Iran

\begin{abstract}
Background: Galanin is a neuropeptide with a wide range of physiological functions that also has stimulatory effects on the reproductive axis. Kisspeptin is a crucial neuropeptide for the stimulation of the reproductive function. In the present study, the interaction of kisspeptin and the galanin signaling system was investigated on the mean serum luteinizing hormone (LH) and the testosterone concentrations in rats. Materials and Methods: Fifty-five male Wistar rats in 11 groups ( $\mathrm{n}=5$ per group) received saline, kisspeptin $(1 \mathrm{nmol}), \mathrm{P} 234(1 \mathrm{nmol})$, galanin $(1 \mathrm{nmol})$, galantide $(1 \mathrm{nmol})$ or simultaneous injections of them via third cerebral ventricle at 07:00 07:30. Blood samples were collected at $30 \mathrm{~min}$ following the injections. Hormone concentrations were measured using rat kit and the method of the radio-immunoassay (RIA). Results: Kisspeptin or galanin injection significantly increased both the mean serum LH and the testosterone concentration compared to saline $(\mathrm{P}<0.05)$. The co-administration of kisspeptin/galanin increased the mean serum LH and the testosterone concentration significantly compared to galanin or saline $(\mathrm{P}<0.05)$. The co-administration of kisspeptin/galanin decreased the mean serum LH concentration compared to kisspeptin, this reduction, however, was not statistically significant. Also, testosterone concentration declined in the kisspeptin/galanin group compared to kisspeptin group. Galantide or p234 injection decreases the mean serum LH and the testosterone concentration compared to galanin and kisspeptin, respectively. The co-administration of galantide/p234 lowers the mean serum LH concentration compared to saline. Conclusion: The interaction of hypothalamic galanin and kisspeptin signaling pathways may play an important role in the modulation of hormonal control of the hypothalamus-pituitary-gonadal axis [GMJ. 2017;6(1):23-29]
\end{abstract}

Keywords: Kisspeptin; Galanin; Galantide; Luteinizing Hormone; Testosterone

\section{Introduction}

$\mathrm{R}$ eproduction is a complex process that is dependent on the energy balance. It is well established that there is a close relationship between metabolism and the hypothalamic-pituitary-gonadal (HPG) axis. Therefore, most of the peptides or hormones involved in

\section{GMJ}

2017 Galen Medical Journal

Tel/Fax: +98 7136474503

PO Box 7193616563

Email:info@gmj.ir controlling the metabolism play a pivotal role in the regulating reproductive axis activity. Galanin is a 29 amino acid (30 in human) peptide which is expressed in the hypothalamic nuclei, especially arcuate nucleus (ARC) and paraventricular nucleus (PVN) [1,2]. It is involved in a wide range of physiological functions running the gamut from modulating the

\footnotetext{
Correspondence to:

Homayoun Khazali, Department of Physiology, Faculty of Biological Sciences, Shahid Beheshti University, Tehran, Iran

Telephone Number: +982122431664

Email address: hkhazali@hotmail.com
} 
pituitary hormone, the control of feeding, the cognitive performance, the energy metabolism, to the thermoregulation and reproduction [2]. Galanin is expressed in the magnocellular hypothalamic neurons such as those in the PVN and supraoptic nuclei (SON); the neurons from these nuclei project to the posterior lob of the pituitary where galanin is released into the portal circulation. In the pituitary, galanin, it has been shown to affect mainly the luteinizing hormone $(\mathrm{LH})$ secretion in the activation of the LH surge and the puberty onset. Previous studies have demonstrated that galanin plays an important role in the regulation of gonadotropin-releasing hormone $(\mathrm{GnRH})$ release $[3,4]$. Interestingly, galanin has also been stated to be co-expressed with $\mathrm{GnRH}$ and kisspeptin [5].

Kisspeptin is a neuropeptide which is mainly expressed in the ARC nucleus of the hypothalamus and plays an essential role in the central regulation of reproduction [6]. It has been found that kisspeptin is implicated in the regulation of the gonadotropin secretion and the regulation preovulatory LH surge. It is also identified to be vital at the onset of puberty [7]. Kisspeptin acts via the $\mathrm{G}$ protein-coupled receptor, GPR54 to stimulate GnRH/LH release [8]. Previous studies have displayed a role for the GPR54 receptor in the development and particularly in the sexual development. These studies have unraveled that the loss of function of the GPR54 receptor, culminates in the hypogonadotropic hypogonadism $(\mathrm{HH})$ and pubertal delay in the humans and rodents [9]. Also, it has been mentioned that the GPR54 knock-out mice display dysfunctional reproduction. The GPR54 is expressed in the GnRH neuron, and kisspeptin directly stimulates the $\mathrm{GnRH}$ and the gonadotropins secretion [10]. In addition, numerous studies have proffered evidence for the fact that the exogenous administration of kisspeptin, either centrally or peripherally, stimulates the HPG axis [11]. Thus, kisspeptin-GPR54 signaling is of the essence for initiating the gonadotropin secretion at puberty and supports the reproductive functions in the adults $[8,10]$.

Some studies have reported the stimulatory effects of galanin or kisspeptin alone on LH and the testosterone secretion. The purpose of this study was to investigate the effects of simultaneous injection of kisspeptin and galanin on the mean serum LH and the testosterone concentration in male rats.

\section{Materials and Methods}

\section{Animals}

Male Wistar Rats $(\mathrm{n}=55)$ weighing 230- 250 $\mathrm{g}$ (provided by the Neuroscience Research Center of Shahid Beheshti University, Tehran, Iran) were housed individually in the cages under the controlled temperature $(22 \pm 2$ $\mathrm{C}^{\circ}$ ) and light (12h light/ dark cycle, light on 0700h). The animals had free access to food and water all the time. All protocols for this research were approved by the ethics committee of Neuroscience Research Shahid Beheshti University of Medical Sciences, Tehran, Iran. All experiments were in accordance with the internationally accepted principles for the Care and Use of Laboratory Animals as found in the US guidelines (NIH Publication No. 8023, revised in 1996).

\section{Intracerebral ventricular (ICV) Cannulation and Injections}

Animals were anesthetized by intraperitoneal (IP) injection of a mixture of Ketamine (alfasan, woerden Holland) and Xylazine (alfasan, woerden Holland) (Ketamine $80 \mathrm{mg} / \mathrm{kg}$ $\mathrm{BW}+$ Xylazine $10 \mathrm{mg} / \mathrm{kg} \mathrm{BW}$ ). For the central injections, a 22- gauge stainless cannula was implanted in the third cerebral ventricle according to the coordinates of Paxinos and Watson Atlas $(\mathrm{AP}=-2.3, \mathrm{ML}=0.0, \mathrm{DV}=6.5$ ) [12]. The cannula was secured to the skull with three stainless steel screws and dental cement. The animals were kept in individual cages. After one-week recovery period, fifty-five rats in 11 groups ( $\mathrm{n}=5$ in each group) received saline, kisspeptin (1nmol), P234 (1nmol), kisspeptin $(1 \mathrm{nmol})+\mathrm{P} 234(1 \mathrm{nmol})$, galanin $(1 \mathrm{nmol})$, galantide $(1 \mathrm{nmol})$, galanin $(1 \mathrm{nmol})+$ galantide $(1 \mathrm{nmol})$, kisspeptin $(1 \mathrm{nmol})+$ galanin (1nmol), kisspeptin(1nmol) + galantide(1nmol), P234(1nmol) + galanin (1nmol), P234 $(1 \mathrm{nmol})+$ galantide $(1 \mathrm{nmol})$, respectively. For the ICV injection, kisspeptin10 (Phoenix Pharmaceutical Inc, USA), P234 (Phoenix Pharmaceutical Inc, USA), galanin (Phoenix Phar- 
maceutical Inc, USA) and galantide (Phoenix Pharmaceutical Inc, USA) were dissolved in saline and were injected by a 27 - gauge stainless steel injector via the third cerebral ventricle at 07:00- 7:30.

\section{Hormones Assays}

Blood samples were collected in a volume of $0.5 \mathrm{cc}$ at $30 \mathrm{~min}$ following the injections. The blood samples immediately centrifuged to $15 \mathrm{~min}$ at $3000 \mathrm{rpm}$ and the serum stored at $-20^{\circ} \mathrm{C}$ until it was assayed for the $\mathrm{LH}$ and testosterone concentration. The serum LH and testosterone concentration were measured by using rat LH kits and the method of the radioimmunoassay (RIA) (Institute of Isotopes Co, LTD, Hungary).

\section{Statistical Analyses}

The results are presented as mean \pm SEM. The data were analyzed by one-way- ANOVA test followed by post hoc Tukey's test and SPSS software (version 16). In all the cases, the statistical significance was defined as $\mathrm{P}<0.05$.

\section{Results}

Kisspeptin increased both the mean serum LH and the testosterone concentration significantly compared to saline $(\mathrm{P}<0.05$, Figure- 1 and 2). Peptide 234 decreased mean serum LH concentration compared to saline, this reduction, nonetheless, was not statistically significant (Figure-1 and 2). The simultaneous injection of kisspeptin and P234 increased the mean serum LH and the testosterone concentration compared to saline, but this increase was not statistically significant (Figure-1 and 2). The simultaneous injection of kisspeptin and P234 decreased the mean serum LH significantly and the testosterone concentration compared to kisspeptin $(\mathrm{P}<0.05$, Figure-1). Galanin significantly increased the mean serum $\mathrm{LH}$ concentration compared to saline $(\mathrm{P}<0.05$, Figure-1). Also, galanin increased the mean serum testosterone concentration compared to saline, this augmentation was statistically significant $(\mathrm{P}<0.05$, Figure- 2$)$. The mean serum LH concentration but not the mean serum testosterone concentration decreased the following galantide injection compared to saline, this decline, however, was not statistically significant (Figure-1 and 2). In addition, our results revealed that in the galantide pretreatment groups, galanin did not significantly increase the LH and testosterone concentrations compared to saline $(\mathrm{P}>0.05)$. The simultaneous injection of galantide and galanin nevertheless, significantly decreased the mean serum LH and the testosterone concentration compared to galanin ( $\mathrm{P}<0.05$, Figure-1 and 2$)$. The mean serum LH and the testosterone concentrations increased significantly following the co-administration of kisspeptin/galanin compared to saline or galanin $(\mathrm{P}<0.05$, Figure-1 and 2$)$. Moreover, the co-administration of kisspeptin/ galanin reduced the mean serum LH as well as the testosterone concentration compared to kisspeptin. Nevertheless, this decrease was not statistically significant $(\mathrm{P}>0.05$, Figure- 1 and 2). The co-administration of kisspeptin/ galantide significantly increased the mean serum $\mathrm{LH}$ and the testosterone concentration compared to saline or galantide ( $\mathrm{P}<0.05$, Figure-1 and 2). The co-administration of P234/ galanin increased the mean serum LH concentration compared to saline or P234 in a statistically significant manner. Furthermore, the co- administration of P234/galanin lowered the mean LH and testosterone concentration compared to galanin. Be that as it may this reduction was not statistically significant $(\mathrm{P}>0.05$, Figure-1 and 2). The co-administration of P234/galantide significantly reduced the mean serum LH concentration compared to saline, $\mathrm{P} 234$ or galantide $(\mathrm{P}<0.05)$. Again, the testosterone concentration decrease was not statistically significant $(\mathrm{P}<0.05$, Figure- 1 and 2).

\section{Discussion}

The effective doses of kisspeptin, P234, galanin and galantide were chosen based on the previous studies [13-15]. The results of this study elucidate that the intracerebroventricular administration of galanin causes a significant increase in the mean serum LH and the testosterone concentration compared to saline. Galantide hampered the stimulatory effects of galanin on LH and testosterone secretion. These results harmonize with the previous 


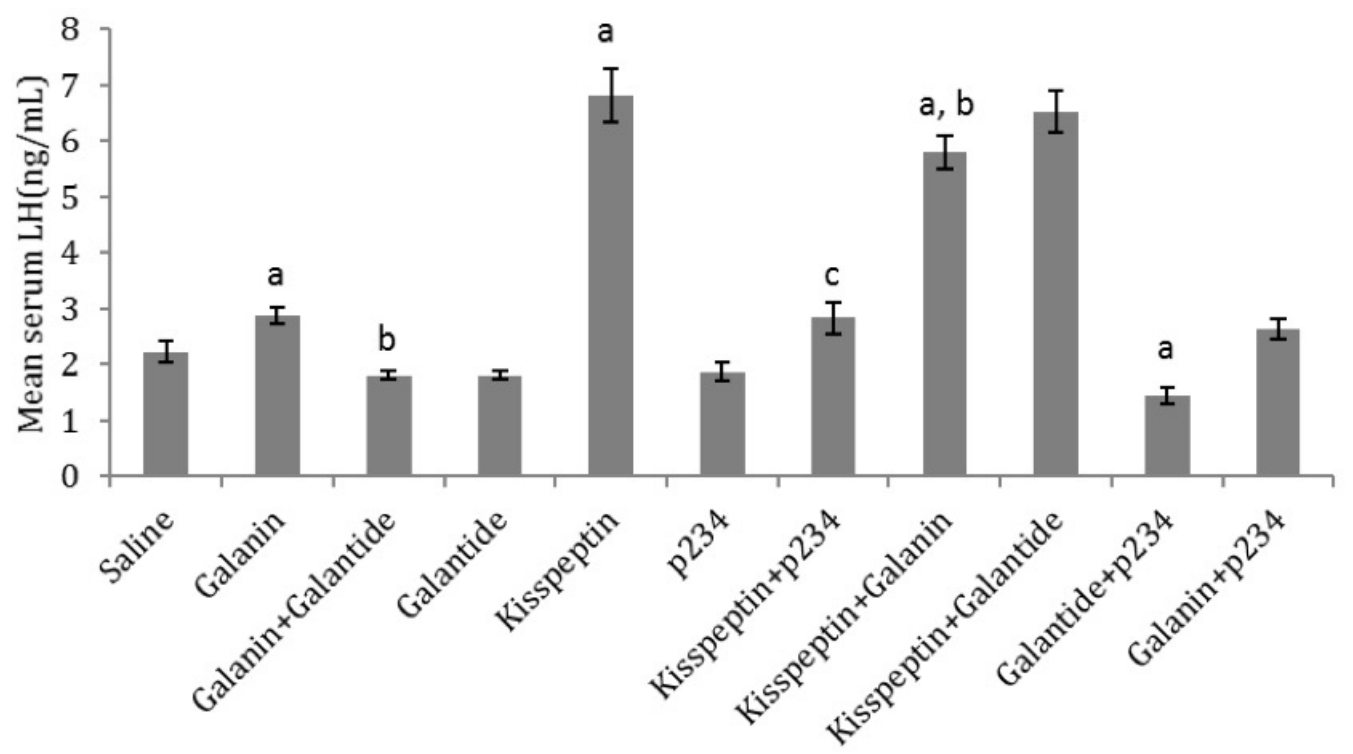

Figure 1. Effects of galanin, galantide, kisspeptin, P234, or the co- administration of kisspeptin/galanim, kisspeptin/galantide, P234/galantide or P234/galanin on the mean serum LH concentration in male Wistar rats. a: compared to saline; b: compared to galanin; c: compared to kisspeptin (data presented the mean \pm SEM, $\mathrm{P}<0.05, \mathrm{n}=5$ in each group).

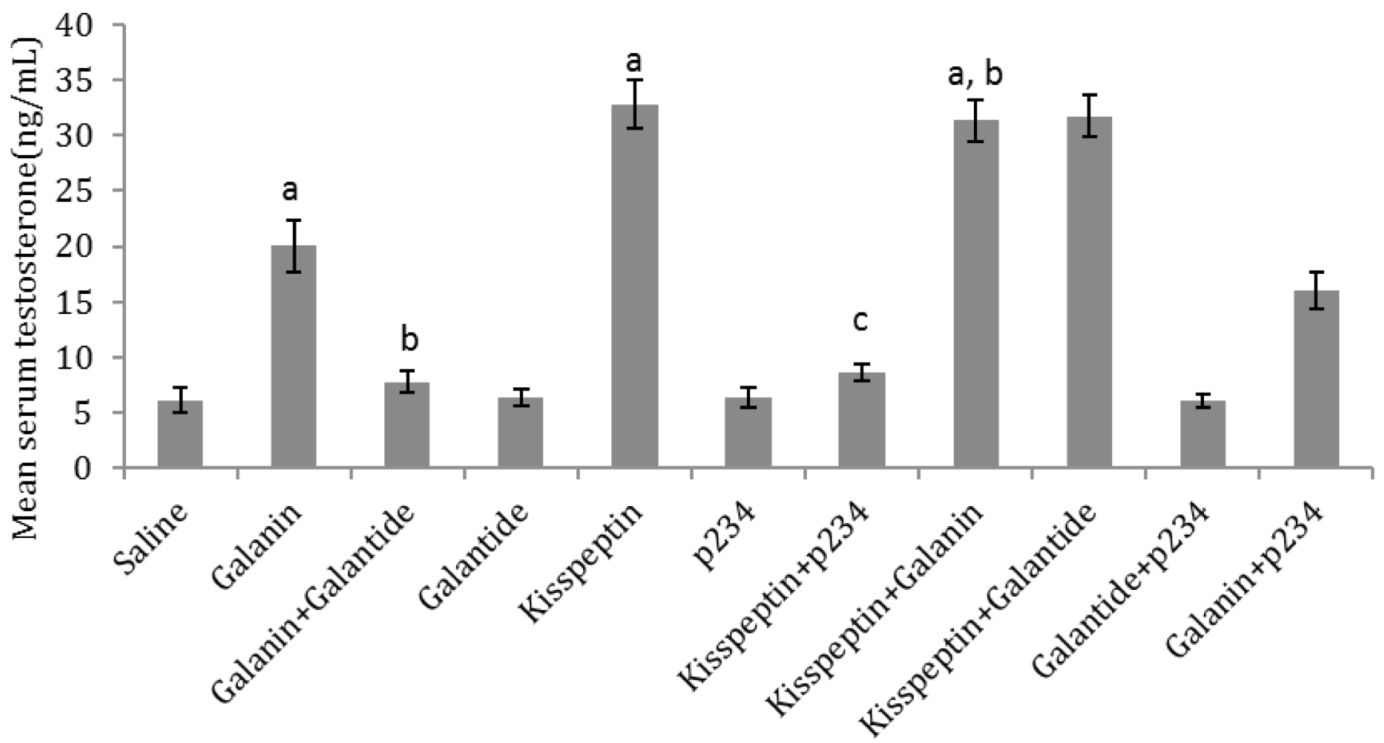

Figure 2. Effects of galanin, galantide, kisspeptin, P234, or the co- administration of kisspeptin/galanim, kisspeptin/galantide, P234/galantide or P234/galanin on the mean serum testosterone concentration in male Wistar rats. a: compared to saline; b: compared to galanin; c: compared to kisspeptin (data presented the mean $\pm S E M, P<0.05, n=5$ in each group).

studies which reported the stimulatory effects of galanin or the inhibitory effects of galantide on galanin action in the HPG axis $[2,14]$. Previous studies have unveiled that galanin plays a quintessential role in the regulation of the reproductive function in rodents such as a pre- ovulatory surge of gonadotropins in females, puberty in males and the GnRH secretion in both females and males. Galanin signaling is mediated through three protein-coupled receptor subtypes (GalR1, GalR2, and GalR3) $[16,17]$. 
GalR1 and GalR3 demonstrated that act through Gi proteins thus have inhibitory effect while GalR2 coupled to Gq type protein [18]. Previous studies have unraveled that galanin affected LH via multifarious mechanisms. Galanin may directly control the pituitary LH secretion. This neuropeptide can reach to the gonadotrophic cells in the pituitary via the hypophyseal portal circulation. Galanin also enhances the GnRH secretion and binding to the GnRH receptor of the pituitary gonadotrophs. It is well established that the galanin nerve terminals synapse on the GnRH cell bodies. It was demonstrated that the number of galanin synapses was higher in the adult female mice compared to the juveniles, this indicates the direct control of galanin in the maturation of the GnRH system [19]. Our results displayed that, the adopted dose of kisspeptin in the present study significantly increased the mean serum LH and testosterone concentration compared to saline. This gives credence to the previous studies. Kisspeptin acts via the G-protein-coupled receptor KISS1R (GPR54) and is a key component of reproduction that directly and indirectly stimulates the HPG axis $[20,21]$. Both the central and peripheral administration of kisspeptin increased the serum LH, follicle-stimulating hormone (FSH), and the total testosterone almost via the stimulation of the GnRH secretion [11,22].

Accordingly, several studies have divulged that two major groups of kisspeptin neurons are in the hypothalamus: A large number in the ARC and a smaller collection in the rostral periventricular area of the third ventricle $(\mathrm{RP} 3 \mathrm{~V})$ of rodents and preoptic area (POA) of non-rodents. The RIA studies have revealed that the highest incident of the GnRH neurons is in contact with the kisspeptin fiber located in the rostral preoptic area and arcuate nucleus $[23,24]$. Kisspeptin neurons have been reported to co-express other neuropeptides. According to the recent evidence, the ARC kisspeptin neurons contain neurokinin $\mathrm{B}$ and dynorphin, while a variable percentage of those cells in the $\mathrm{RP} 3 \mathrm{~V}$ of rodents contain galanin, dopamine and/or metenkephalin. Neurokinin B and dynorphin were involved in the control of GnRH pulses and the sex steroid negative feedback, while the role of galanin in kisspeptin neurons is not entirely clear. Most of the cell neurons in the RP3V are IP for galanin, and one-third of them express galanin mRNA. Galanin-immunoreactivity also occurs in the subsets of the KP neurons in the ARC $[5,25,26]$. Based on the phylogenetic analysis of the neuropeptide receptors GalR and Kiss1R are phylogenetically close to each other amongst other peptide GPCR families; moreover, Kiss1R shares 45\% identity with the galanin receptors [27]. Also, the expression pattern of Kiss $1 \mathrm{R}$ was observed to resemble that of the GalR [6].

In the current study, we investigated the effects of the central simultaneous injections of kisspeptin and galanin on the mean serum LH and testosterone concentration. The co-administration of kisspeptin and galanin decreased the means of LH and total testosterone compared to kisspeptin alone, but these decreases were not significant. It worthy of mentioning that the present study for the first time has zeroed in on the effects of interaction of galanin and kisspeptin on LH and testosterone secretions in male rats, therefore, there has been no previous studies to compare the results. Recently Constantino and Wray reported that galanin inhibits kisspeptin induced GnRH neuronal activity the scrutiny of which could be accounted as a testimony to the results elicited from the present study [28].The presence of GalR1 and GalR2 in the GnRH neurons has been reported; nonetheless, the GalR2 was only present in a small subpopulation of $\mathrm{GnRH}$ neurons and GalR1 is dominant. The GalR1 activation opens the G-protein-regulated inwardly rectifying $\mathrm{K}+$ (GIRK) channels [29] and stimulates the mitogen-activated protein kinase (MAPK) activity in a protein kinase $\mathrm{C}$ (PKC) [30]. The GalR1 has exhibited an inhibitory effect on the GnRH neurons and can obstruct the stimulatory effect of kisspeptin on these neurons and the kisspeptin induced calcium responses [28].

\section{Conclusion}

The findings of this study depicted that the central injection of kisspeptin or galanin significantly increased the mean serum LH and testosterone concentration compared to saline and the co-administration of kisspeptin and galanin decreased the mean serum LH con- 
centration compared to kisspeptin. In a nutshell, our results suggest that the interaction between galanin and kisspeptin may modulate the reproductive function.

\section{Acknowledgment}

The authors would like to thank Dr. Fariba Mahmoudi for her invaluable help in all pro- cess of the study and the personnel of the Neuroscience Research Center of Medical Sciences at Shahid Beheshti University.

\section{Conflict of Interest}

The authors declare no conflicts of interest and have approved the final article.

\section{References}

1. Crown A, Clifton DK, Steiner RA. Neuropeptide signaling in the integration of metabolism and reproduction. Neuroendocrinology. 2007;86(3):175-82.

2. Fang P, He B, Shi M, Kong G, Dong $\mathrm{X}, \mathrm{Zhu} \mathrm{Y}$, et al. The regulative effect of galanin family members on link of energy metabolism and reproduction. Peptides. 2015;71:240-9.

3. Landry M, Roche D, Angelova E, Calas A. Expression of galanin in the hypothalamic magnocellular neurons of lactating rats: coexistence with vasopressin and oxytocin. J Endocrinol. 1997;155(3):467-81.

4. Merchentaler I. Galanin and the neuroendocrine axes. EXS. 2010;102:71-85.

5. Kallo I, Vida B, Deli L, Molna CS, Hrabovszky E, Caraty A, et al. CoLocalisation of Kisspeptin with Galanin or Neurokinin B in Afferents to Mouse GnRH Neurones. J Neuroendocrinol. 2012;24(3):464-76.

6. Messager S, Chatzidaki EE, Ma D, Hendrick AG, Zahn D, Dixon J, et al. Kisspeptin directly stimulates gonadotropin-releasing hormone release via $\mathrm{G}$ protein-coupled receptor 54. Proc Natl Acad Sci U S A. 2005;102(5):1761-6.

7. Colledge WH. GPR54 and puberty. Trends Endocrinol Metab. 2004;15(9):448-53.

8. Han SK, Gottsch ML, Lee KJ, Popa SM, Smith JT, Jakawich SK, et al. Activation of gonadotropin-releasing hormone neurons by kisspeptin as a neuroendocrine switch for the onset of puberty. J Neurosci. 2005;25(49):11349-56.

9. d'Anglemont de Tassigny X, Fagg LA, Dixon JP, Day K, Leitch HG, Hendrick AG, et al.
Hypogonadotropic hypogonadism in mice lacking a functional Kiss1 gene. Proc Natl Acad Sci U S A. 2007 Jun 19;104(25):107149.

10. Herbison AE, de Tassigny Xd, Doran J, Colledge WH. Distribution and postnatal development of Gpr54 gene expression in mouse brain and gonadotropin-releasing hormone neurons. Endocrinology. 2010;151(1):312-21.

11. Thompson EL, Patterson M, Murphy KG, Smith KL, Dhillo WS, Todd JF, et al. Central and peripheral administration of kisspeptin-10 stimulates the hypothalamicpituitary-gonadal axis. J Neuroendocrinol. 2004;16(10):850-58.

12. Paxinos $\mathrm{G}$, Watson $\mathrm{C}$. The rat brain in stereotaxic coordinates. 5th ed. San Diego: Academic Press; 2005.

13. Dube MG, Horvath TL, Leranth C, Kalra PS, Kalra SP. Naloxone reduces the feeding evoked by intracerebroventricular galanin injection. Physiol Behav. 1994;56(4):811-13.

14. Pandit MA, Saxena RN. Galanin regulation of LH release in male rats. Indian J Exp Biol. 2010;48(6):544-48.

15. Mahmoudi F, Khazali H, Janahmadi M. Interactions of morphine and Peptide 234 on mean plasma testosterone concentration. Int J Endocrinol Metab. 2014;12(1):e12554.

16. Branchek TA, Smith KE, Gerald C, Walker MW. Galanin receptor subtypes. Trends Pharmacol Sci. 2000;21(3):109-17.

17. Whitelaw CM, Robinson JE, Hastie PM, Padmanabhan V, Evans NP. Effects of cycle stage on regionalised galanin, galanin receptors 1-3, GNRH and GNRH receptor mRNA expression in 
the ovine hypothalamus. J Endocrinol 2012;212(3):353-61.

18. Lang R, Gundlach AL, Kofler B. The galanin peptide family: Receptor pharmacology, pleiotropic biological actions, and implications in health and disease. Pharmacol Ther. 2007;115(2):177-207.

19. Rajendren G, Li X. Galanin synaptic input to gonadotropin-releasing hormone perikarya in juvenile and adult female mice: implications for sexual maturity. Brain Res Dev Brain Res. 2001;131(1-2):161-65.

20. Pielecka-Fortuna J, Chu Z, Moenter SM. Kisspeptin acts directly and indirectly to increase gonadotropin-releasing hormone neuron activity and its effects are modulated by estradiol. Endocrinology. 2008;149(4):1979 -986

21. Clarksona J, Hanb SK, Liua X, Leea K, Herbisona AE. Neurobiological mechanisms underlying kisspeptin activation of gonadotropin-releasing hormone (GnRH) neurons at puberty. Mol Cell Endocrinol. 2010;324(1-2):45-50.

22. Patterson M, Murphy KG, Thompson EL, Patel S, Ghatei MA, Bloom SR. Administration of kisspeptin-54 into discrete regions of the hypothalamus potently increases plasma luteinising hormone and testosterone in male adult rats. $\mathrm{J}$ Neuroendocrinol. 2006;18(5):349-54.

23. Clarkson J, Herbison AE. Postnatal development of kisspeptin neurons in mouse hypothalamus; sexual dimorphism and projections to gonadotropin-releasing hormone neurons. Endocrinology. 2006;147(12):5817-25.
24. Clarkson J, Herbison AE. Dual Phenotype Kisspeptin-dopamine neurones of the rostral periventricular area of the third ventricle project to gonadotrophin-releasing hormone neurones. J Neuroendocrinol 2011;23(4):293301.

25. Porteous R, Petersen SL, Yeo SH, Bhattarai JP, Ciofi P, de Tassigny XD, et al. Kisspeptin neurons co-express met-enkephalin and galanin in the rostral periventricular region of the female mouse hypothalamus. J Comp Neurol. 2011;519(17):3456-69.

26. Yeo SH. Neuronal circuits in the hypothalamus controlling gonadotrophinreleasing hormone release: the neuroanatomical projections of kisspeptin neurons. Exp Physiol. 2013;98(11):1544-9.

27. Yun S, Kim DK, Furlong M, Hwang JI, Vaudry H, Seong JY. Does Kisspeptin Belong to the Proposed RF-Amide Peptide Family?. Front Endocrinol (Lausanne). 2014;5:134.

28. Constantin S, Wray S. Galanin activates G-protein gated inwardly rectifying potassium channels and suppresses kisspeptin-10 activation of GnRH neurons. Endocrinology. 2016;157(8):3197-212.

29. Smith KE, Walker MW, Artymyshyn R, Bard J, Borowsky B, Tamm JA, et al. Cloned human and rat galanin GALR3 receptors. Pharmacology and activation of G-protein inwardly rectifying $\mathrm{K}+$ channels. J Biol Chem. 1998; 273(36):23321-6.

30. Wang S, Hashemi T, Fried S, Clemmons AL, Hawes BE. Differential intracellular signaling of the GalR1 and GalR2 galanin receptor subtypes. Biochemistry. 1998;37(19):6711-7. 